\title{
A Field Investigation of Meiofaunal Dispersal: Tidal Resuspension and Implications
}

\author{
S. S. Bell ${ }^{1}$ and K. M. Sherman ${ }^{2}$ \\ ${ }^{1}$ Department of Biology, University of South Florida, Tampa, Florida 33620, USA \\ ${ }^{2}$ Department of Oceanography, Florida State University, Tallahassee, Florida 32306, USA
}

\begin{abstract}
Presence of meiofauna in resuspended sediments was investigated in a tidal creek system employing a specially designed core sampler and quick freezing techniques. Forty core samples were taken during 4 successive ebb tides to determine the distribution of meiofauna in (a) overlying water; (b) resuspended sediment; and (c) undisturbed sediment fractions of each sample. Our experiments demonstrate that $13-44 \%$ of the meiobenthic copepod subcommunity was present in overlying and resuspended sediment fractions, while only a small percentage of nematodes was found simultaneously in these layers. We suggest that selected meiofauna may disperse through tidally coupled mechanisms and that such phenomena should be addressed in demographic and community studies.
\end{abstract}

\section{INTRODUCTION}

Dispersal of individuals is an important, often unevaluated, demographic parameter (e.g. Gadgil, 1971). It is of critical interest in discussions of gene flow and genetic variability (Scheltema, 1971; Crisp, 1978), biogeography (Scheltema, 1977, and references within) and recolonization and successional processes (Connell and Slayter, 1977) in the marine environment. Although dispersal mechanisms of marine macrofauna have received attention in the above studies, little is known about dispersal of their smaller, meiobenthic counterparts. Theories on meiofaunal dispersal have been generated from anecdotal or indirect evidence and biogeographic distributions (Por, 1969; Sterrer, 1973; Scheibel, 1974; Gerlach, 1977), but in general there is a paucity of the observational or empirical evidence needed to support such formulations. In fact, many meiobenthic researchers dismiss movement of meiofauna as unimportant simply because we have no information on transport of these benthic inhabitants (Bell, in press). We feel that this approach is no longer acceptable given the ever increasing interest in charting meiofaunal population abundance and community changes (see Coull and Bell, 1979 for review).

Those researchers who have addressed the topic of meiofaunal dispersal (e.g. Sterrer, 1973; Gerlach, 1977; Boaden, 1968) acknowledge that resuspension and transport of sand-dwelling meiofauna is possible, but that most of these meiofauna have morphological or behavioral adaptations that protect against transport out of the system. On the other hand, transport of meiofauna in mud habitats has not been examined. It is possible that mud-dwelling meiofauna might be transported with moving tidal waters or currents given that (1) meiofauna in mud systems are generally larger, burrowing forms without adhesive organs in contrast to the smaller, interstitial groups characteristic of sandy sediments; (2) the former are found in greatest abundance in surface sediment layers (Coull and Bell, 1979); and (3) resuspension of top sediment layers is a widespread phenomenon readily observed in shallow mud systems (Rhoads et al., 1975; 1978).

A major problem in evaluating whether meiofauna are dispersed in situ through resuspension is that adequate sampling techniques which themselves do not introduce structural artifacts (e.g. sediment traps) or resuspend sediment particles or associated meiofauna have not been available. Therefore, the purpose of our study was twofold: (1) to design an effective sampler for discrete collection of overlying water, resuspended flocculent layers, and undisturbed sediment, and (2) to determine experimentally whether populations of meiofauna are present in moving waters or flocculent layers.

\section{METHODS AND MATERIALS}

\section{Sampling Device}

A diagramatic outline of our sampling device is presented in Figure 1. Our sampler was constructed 


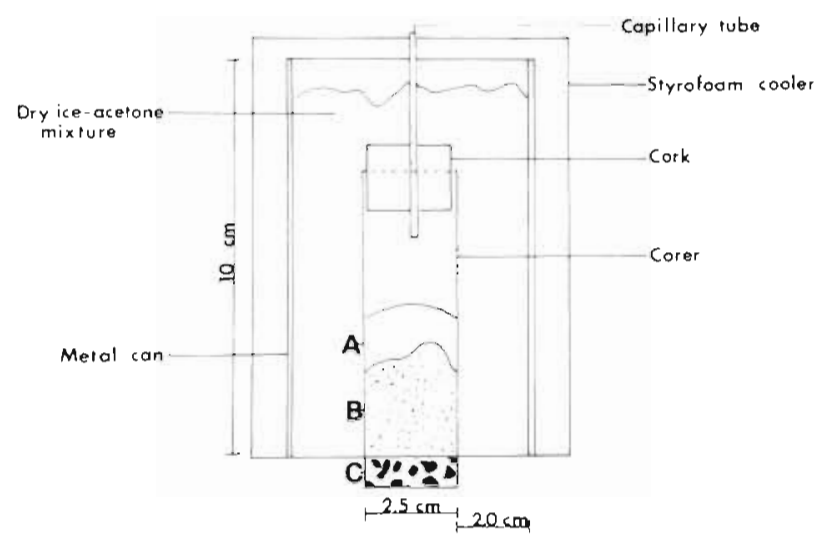

Fig. 1. Schematic outline of sediment-water sampler. A: Fraction 1; B: Fraction 2; C: Fraction 3

out of a $236 \mathrm{ml}$ 'soup' can $(10 \mathrm{~cm}$ high $\times 6.5 \mathrm{~cm}$ diameter) with one end removed. A $2.6 \mathrm{~cm}$ hole was punched in the remaining end and a $2.5 \mathrm{~cm}$ inner diameter plastic core ( $8 \mathrm{~cm}$ in length) was inserted through this opening, extending $1 \mathrm{~cm}$ from the lower end of the container. A cork with capillary tubing sealed the top end of the core inside the sampler.

Prior to sampling, dry ice was packed around the plastic core inside the metal can, and the entire sampling device was then placed into an insulated cooler and kept cold until used in field sampling.

\section{Sampling}

For sampling, cores were transported to the field in a cooler. Cores were carefully lowered through the overlying water (approximately $6 \mathrm{~cm}$ deep at time of sampling) and the upper $1 \mathrm{~cm}$ of sediment while simultaneously pouring acetone (reagent grade) into the area packed with dry ice. The contents of the plastic core were thereby frozen quickly. A laboratory check on our methodology demonstrated that sediments were not resuspended inside the corer by our sampling procedure. Previous laboratory experiments showed also that the dry ice slurry was able to lower seawater temperature from $20^{\circ} \mathrm{C}$ to $-5^{\circ} \mathrm{C}$ within $25 \mathrm{~s}$ (Bell, personal observation). After the core was positioned, a styrofoam holder was placed over the apparatus to aid in the freezing process. After approximately $3 \mathrm{~min}$, cores were removed, replaced in the cooler, and quickly returned to the laboratory for processing.

Our experimental study site was located in a tidal creek bordering a Spartina alterniflora Loisel marsh in North Inlet, Georgetown, S.C., USA $\left(30^{\circ} 21.0^{\prime} \mathrm{N}\right.$, $\left.79^{\circ} 11.5^{\prime} \mathrm{W}\right)$. The overlying water temperature at time of sampling was $30^{\circ}-32^{\circ} \mathrm{C}$ and sediments had a median grain size of $\varnothing=2$. All samples were taken $1 \mathrm{~h}$ before mean low water at which time water depth was approximately $5-7 \mathrm{~cm}$. During this time, rapidly moving tidal waters and a conveyor belt motion of resuspended flocculent material were readily observed. Although current velocities were not measured in our study, previous investigations have found current velocity range from $0-60 \mathrm{~cm} \mathrm{~s}^{-1}$ at the mouth of this creek (L. R. Gardener, personal communication). We specifically chose to sample at this stage in the tidal cycle so that we could employ our sampling device $10 \mathrm{~cm}$ in height). Additionally, since we were interested in establishing only whether meiofauna were present in overlying water and/or resuspended sediment layers, it was not essential for our purposes to extend sampling over the entire tidal period. Samples were taken in 2-5 transects across a tidal creek and samplers were directed into place by persons standing on adjacent creek banks. Care was taken not to disturb the area prior to sampling and each sampler was sufficiently far apart from adjacent ones (at least $60 \mathrm{~cm}$ ) so that any disturbance created during the sampling procedure would not interfere with subsequent collections. Four sets of samples $(n=40)$ were taken during successive ebb tides (i.e. 2 night and 2 day sets) on August 7-8, 1979.

In the laboratory the dry ice slurry was discarded and the frozen sediment and water cores were extruded from the sampler. The frozen cores were then placed in Whirlpaks ${ }^{\mathrm{TM}}$ and stored in a freezer $\left(0^{\circ} \mathrm{C}\right)$. For further processing, cores were removed from the freezer, slightly thawed for 10 mins, and carefully fractionated into 2-3 segments based on the following characteristics: Fraction 1 - clear; overlying water; Fraction 2 cloudy, resuspended flocculent layer; Fraction 3 - top $1.0 \mathrm{~cm}$ sediment (Fig. 1).

The distinction between Fractions 1 and 2 was not always obvious and the two fractions were combined in some cores (e.g. 1420, 8-8-79; Table 1); however, the delineation between the sediment and overlying flocculent materials (Fractions 2 and 3 ) was easily visible. After separation, each fraction was completely thawed, washed through a $63 \mu \mathrm{m}$ mesh seive, and preserved with Rose Bengal and $10 \%$ formalin. Meiofauna from all fractions were enumerated under a dissecting microscope. Copepods were identified to species in all core fractions. Nematode species were determined from all water and resuspended sediment layers and 4 randomly selected sediment cores within each set.

\section{RESULTS}

The results of our experiment are presented in Table 1. Nematodes and copepods were the most abundant meiofauna taxa recorded in each core fraction, although juvenile bivalves and polychaetes were occa- 
Table 1. Mean densities $5.1 \mathrm{~cm}^{-2}$ ( $\pm 1 \mathrm{~s}$. e.) of most abundant meiofauna taxa recorded from each of the three core fractions as described in Figure 1 over sampling interval. Numbers in parentheses refer to mean relative percent abundance of meiofauna taxa for each sampling time. n: number of successful samples per sampling period

\begin{tabular}{|c|c|c|c|c|}
\hline $\begin{array}{l}\text { Date } \\
\text { Time }\end{array}$ & $\begin{array}{c}8-7-79 \\
0100\end{array}$ & $\begin{array}{c}8-7-79 \\
1400\end{array}$ & $\begin{array}{c}8-8-79 \\
0230\end{array}$ & $\begin{array}{c}8-8-79 \\
1420\end{array}$ \\
\hline Fraction 1 (water) & $\mathrm{n}=6$ & $\mathrm{n}=9$ & $n=7$ & $\mathrm{n}=6$ \\
\hline Nematodes & $\begin{array}{r}1.4 \\
\pm \quad 0.3(1.0)\end{array}$ & $\begin{array}{r}2.3 \\
\pm \quad 0.6\end{array}$ & $\begin{array}{r}2.6 \\
\pm \quad 0.4(2.0)\end{array}$ & $\begin{array}{r}1.6 \quad(1.6) \\
\pm 1.0\end{array}$ \\
\hline Copepods & $\begin{array}{r}1.4 \\
\pm \quad 1.0(19.0)\end{array}$ & $\begin{array}{r}2.0 \\
\pm \quad 0.7(18.0)\end{array}$ & $\begin{array}{r}0.57 \\
\pm \quad 0.3 \quad(7.0)\end{array}$ & $\begin{aligned} & 5.6 \\
+ & 2.2\end{aligned}(44.4)$ \\
\hline Nauplii & $\begin{array}{r}1.8 \\
\pm \quad 0.6\end{array}(10.0)$ & $\begin{array}{r}12.0 \\
\pm \quad 0.6\end{array}$ & $\begin{array}{r}1.2 \\
+0.7(13.0)\end{array}$ & $\begin{array}{r}28.5 \\
\pm 14.0\end{array}$ \\
\hline Fraction 2 (resuspended sediment) & $\mathrm{n}=3$ & $\mathrm{n}=8$ & $\mathrm{n}=6$ & \\
\hline Nematodes & $\begin{array}{r}1.0 \\
\pm \quad 0.9(1.0)\end{array}$ & $\begin{array}{r}2.7(3.0) \\
\pm \quad 1.0 \quad(3.0\end{array}$ & $\begin{array}{r}1.1(0.9) \\
\pm 0.6 \quad(1)\end{array}$ & \\
\hline Copepods & $\begin{array}{r}0.5 \\
\pm \quad 0.2(6.0)\end{array}$ & $\begin{array}{r}1.2 \\
\pm \quad 0.5(11.0)\end{array}$ & $\begin{array}{r}0.5 \\
\pm \quad 0.3 \quad(6.0)\end{array}$ & \\
\hline Nauplii & $\begin{array}{r}1.0 \\
\pm \quad 0.7(13.0)\end{array}$ & $\begin{array}{r}8.5 \\
+\quad 4.2(27.6)\end{array}$ & $\begin{array}{r}2.6 \\
\pm \quad 0.8\end{array}(28.0)$ & \\
\hline Fraction 3 (sediment) & $\mathrm{n}=6$ & $\mathrm{n}=9$ & $n=7$ & $\mathrm{n}=6$ \\
\hline Nematodes & $\begin{array}{r}84.0 \\
\pm \quad 0.7(98.0)\end{array}$ & $\begin{array}{r}87.0 \\
\pm 17.0 \\
\end{array}$ & $\begin{array}{r}108.0 \\
\pm 25.3\end{array}$ & $\begin{array}{r}96.3 \\
\pm 18.0 \\
(98.4)\end{array}$ \\
\hline Copepods & $\begin{array}{r}5.6 \\
\pm \quad 1.0\end{array}(75.0)$ & $\begin{array}{r}7.8 \\
\pm \quad 2.0(71.0)\end{array}$ & $\begin{array}{r}7.3 \\
+\quad 1.3(87.0)\end{array}$ & $\begin{array}{r}7.0 \\
+\quad 2.0\end{array}(55.6)$ \\
\hline Nauplii & $\begin{array}{r}15.0 \\
\pm \quad 6.0\end{array}$ & $\begin{array}{r}10.2 \\
\pm \quad 3.8\end{array}$ & $\begin{array}{r}5.5 \\
\pm \quad 1.4 \\
(59.0)\end{array}$ & $\begin{array}{r}14.3 \\
+\quad 3.2\end{array}$ \\
\hline
\end{tabular}

sionally found in sediment core segments. During all four sampling periods meiofauna taxa were found in overiying water and resuspended sediment layers supporting our theory of meiofaunal dispersal. However, the relative abundance of specific meiofauna taxa was markedly different for the most abundant groups found at this site. Nematodes dominated the sediment Fractions 3 and were found in very low percentages in other fractions (Table 1). However, Fractions 1 and 2 together contained up to a mean of $48.0 \%$ of adult copepods and $66.5 \%$ of nauplii found in all core fractions (Table 1). This evidence suggests that a significant proportion of a meiobenthic copepod assemblage (both adults and nauplii) is present in tidal waters in association with resuspended sediments and overlying waters.

When analyzed at the species level, the most common meiobenthic copepods identified from the three core fractions were Halicyclops coulli Herbst, Microarthridion littorale Poppe and Enhydrosoma propinquum (Brady). The first two of these species are relatively large epibenthic forms while E propinquum is smaller, and generally thought to be a burrower (Coull and Vernberg, 1970; Bell, 1979). In sediment Fractions 3 an additional species, Nitocra sp., was encountered but was never found in the upper two fractions. Unfortunately, we were unable to identify nauplii to species.

The nematode fauna from sediment core fractions was overwhelmingly dominated by Theristus sp. with
Ptycholaimellus pandispiculatus Hopper and Metachromadora pulvinata Wieser and Hopper ranking second and third in abundance, respectively. Although the number of nematodes found in Fractions 1 and 2 was low, there was no difference in the relative abundance of nematode species in sediment and upper core fractions; those species that were dominant in the sediment had the most individuals in the upper fractions as well.

The sampling technique described in this study appeared to work well in our shallow tidal creek system. The number of successful samples varied from $60-90 \%$ per sampling interval (Table 1) and lost samples were due to either irregular bottom topography (e.g. oyster shells, burrows) not visible through murky water or incomplete freezing (2 cases). The absolute number of meiofauna recorded from overlying water and flocculent layers probably represents a minimum estimate of meiofauna in these layers since meiofauna may move away from cold temperatures (but see Uhlig, 1968). Again, our objective was to establish specifically whether meiofauna were found in the upper two core fractions and our sampling techniques demonstrated clearly this is true.

\section{DISCUSSION}

Our study illustrates that meiobenthic copepods from mud-dwelling habitats are present in overlying 
water layers and resuspended sediments. The phenomena of current and tidal resuspension are widespread and have been emphasized as being common in estuaries. These phenomena may also have important implications for increasing nutritive values of resuspended material (Rhoads et al., 1975; Tenore, 1976; Roman and Tenore, 1978), and influencing sediment characteristics (Van Straaten and Kuenen, 1958) and survival of benthos (Rhoads and Young, 1970; McCall, 1978). In addition, our findings suggest strongly that tidal resuspension may provide a mechanism for selected meiofaunal dispersal.

Macrofaunal organisms may affect upper sediment layers and thus resuspension of meiofauna. For instance, Rhoads and Young (1970) have shown that infauna alter sediment characteristics and erodibility, and such modifications therefore may influence dispersal of meiofauna. Likewise, macroepifauna such as grass shrimp and larval fish may indirectly influence dispersal through their feeding activities, which create clouds of flocculent material that move with tidal waters (Bell, unpubl.). Therefore, biological interactions between macrofauna and meiofauna may be more prevalent than previously acknowledged (Bell, in press and references within).

Our study reemphasizes the importance of identifying or distinguishing between processes that influence interstitial (sand) meiofauna compared to larger, muddwelling forms. Although Boaden (1968) reported that interstitial forms moved into lower sediment depths to avoid being transported with water, evidence presented here suggests that some copepods do not follow this mode of behavior. Interestingly, Hauspie and Polk (1973) noted the potential for some harpacticoid copepods to swim but information is not available to determine whether the copepods from our study site act selectively to increase their probability of dispersal. A number of authors have investigated the behavioral correlates of macrofaunal migrations and hydrographic parameters in sandy beach systems (e.g., Cubit, 1969; Trueman, 1971), and, analogously, similar behavioral patterns may play a previously ignored yet critical role in animal movement in the smaller, meiofaunal system discussed above.

Our results did not demonstrate that a large number of nematodes was present in flocculent layers or overlying water. This is curious since Sherman (1979) reported that nematodes were capable of recolonizing depopulated sediment after one tidal cycle. Possibly, our technique is not suitable for trapping nematodes in the upper fractions because of some, as yet unknown reason. It is also possible that the nematodes move during different stages of a tidal cycle, and further studies on this topic certainly are warranted.

Perhaps one of the most important implications of our study is the necessity for acknowledgement and reevaluation of dispersal capabilities of meiobenthic copepods. We are aware of no study on meiobenthic copepod communities or populations which has critically examined or discussed the possible consequences of meiofaunal dispersal on population dynamics or community changes (or lack of same). For example, marked changes in copepod abundance recorded over years in the North Inlet system (Bell, 1979; Coull, personal communication) may be a direct result of uncharted transport or recruitment of copepods into study sites. Our findings challenge investigations to reconsider and examine experimentally former predictions on meiofauna dispersal. To this end it would be instructive to expand studies on meiofaunal dispersal to other mud systems and compare transport of meiofauna under a wide variety of hydrodynamic conditions. We feel that our study provides a preliminary foundation for future efforts in this field.

Acknowledgements. This study was supported by a National Science Foundation Grant OCE 78-27564 to S.S. Bell. Special thanks belong to J. Willard Bell who spent many hours designing the sampling device. We would also like to thank Ardis $M$. Savory who initially emphasized the importance of this project. Bruce C. Coull, Margaret A. Palmer, and Earl D. McCoy provided stimulating discussions and valuable comments on an earlier draft of the manuscript. Finally, we would like to acknowledge Dr. F. John Vernberg and the Belle W. Baruch Institute of Marine Biology and Coastal Research for the use of their facilities.

\section{LITERATURE CITED}

Bell, S. S. (1979). Short- and long-term variation in a high marsh meiofauna community. Estuar. \& Coast. mar. Sci. 9: 331-350

Bell, S. S. (in press). Meiofauna-macrofauna interactions in a high salt marsh habitat. Ecology

Boaden, P. J. S. (1968). Water movement - a dominant factor in interstitial ecology. Sarsia 34: 125-136

Connell, J. H., Slayter, R. O. (1977). Mechanisms of succession in natural communities and their role in community stability and organization. Am. Nat. 111: 1119-1144

Coull, B. C., Bell, S. S. (1979). Perspectives of marine meiofaunal ecology. In: Livingston, R. J. (ed.) Ecological processes in coastal and marine ecosystems, New York, Plenum Press, pp. 189-216

Coull, B. C., Vernberg, W B. (1970). Harpacticoid copepod respiration: Enhydrosoma propinquum and Longipedia helgolandica. Mar. Biol. 5: 341-344

Crisp, D. J. (1978). Genetic consequences of different reproductive strategies in marine invertebrates. In: Battaglia, B., Beardmore, J. (ed.) Marine organisms. Plenum Press. New York, pp. 257-273

Cubit, J. (1969). Behavior and physical factors causing migration and aggregation of the sand crab Emerita analoga (Stimpson). Ecology 50: 118-123

Gadgil, M. (1971). Dispersal: population consequences and evolution. Ecology 52: 253-261 
Gerlach, S. A. (1977), Means of meiofauna dispersal. Mikrof. Meeresb. 61: 89-103

Hauspie, R., Polk, P. H. (1973). Swimming behavior patterns in certain benthic harpacticoids. Crustaceana 25: 95-103

McCall, P. L. (1978). Spatial-temporal distributions of Long Island Sound infauna: the role of bottom disturbance in a nearshore marine habitat. In: Wiley, M. L. (ed.) Estuarine interactions. New York, Academic Press, pp. 191-219

Por, F. D. (1969). The Canuellidae (Copepoda, Harpacticoida) in the waters around the Sinai peninsula and the problem of 'Lessepsian' migration of this family. Israel J. Zool. 18: $169-178$

Rhoads, D. C., Young, D. K. (1970). The influence of depositfeeding organisms on sediment stability and community trophic structure. J. mar. Res. 28: 150-178

Rhoads, D. C., Tenore, K. R., Browne, M. (1975). The role of suspended bottom mud in nutrient cycles of shallow embayments. In: Cronin, L. E. (ed.) Estuarine research. I. Chemistry, biology and the estuarine system. Academic Press, New York, pp. 563-579

Rhoads, D. C., Yingst, J. Y., Ullman, W. J. (1978). Seafloor stability in central Long Island Sound: Part I. Temporal changes in erodability of fine-grained sediment. In: Wiley, M. L. (ed.) Estuarine interactions. Academic Press, New York, pp. 221-244

Roman, M. R., Tenore, K. R. (1978). Tidal resuspension in Buzzards Bay, Massachusetts. 1 . Seasonal changes in the resuspension of organic carbon and chlorophyll a. Estuar. $\&$ Coast. mar. Sci. 6: $37-46$
Scheibel, W (1974). Submarine experiments on benthic colonization of sediments in the Western Baltic Sea. Mar. Biol. 23: $165-168$

Scheltema, R. S. (1971). Larval dispersal as a means of genetic exchange between geographically separated populations of shallow-water benthic marine gastropods. Biol Bull mar biol. Lab., Woods Wole 140: 284-322

Scheltema, R. S. (1977). Dispersal of marine invertebrate organisms: paleobiogeographic and biostratigraphic implications. In: Kauffman, E. G., Hazel, J. E. (eds) Concepts and methods of biostratigraphy. Hutchinson and Ross, Inc., Stroudsburg, Pennsylvania, pp. 73-120

Sherman, K. M. (1979). The response of marine meiobenthos to man-made disturbance. M. S. thesis, University of South Carolina, Columbia

Sterrer, W. (1973). Plate tectonics as a mechanism for dispersal and speciation in interstitial sand fauna. Neth. J. Sea Res. 7: 200-222

Tenore, K. R. (1976). Food chain pathways in benthic communities: A review, with new observations on sediment resuspension and detrital recycling. In: Coull, B. C. (ed.) Ecology of marine benthos. University of South Carolina Press, Columbia, South Carolina, pp. 37-53

Trueman, E. R. (1971). The control of burrowing and the migratory behavior of Donax denticulatus (Bivalvia: Tellinacea). J. Zool. 165: 453-469

Uhlig, G. (1968). Quantitative methods in the study of interstitial fauna. Trans. Am. microsc. Soc. 87: 226-232

Van Straaten, L. M. J. U., Kuenen, P. H. (1958). Tidal action as a cause of clay accumulation. J. sedim. Petrol. 28: 406-413 